\title{
ARE YOU BULLIED? : EMPATHY CHARACTER BUILDING TRAINING PADA SISWA SEKOLAH DASAR
}

\author{
ARE YOU BULLIED? : EMPATHY CHARACTER BUILDING TRAINING \\ ON BASIC SCHOOL STUDENTS
}

\author{
Submited : \\ 9 Januari 2019 \\ Revision : \\ 6 Februari 2019 \\ Accepted : \\ 29 Maret 2019
}

\author{
Oleh : \\ Yuliezar Perwira Dara ${ }^{1}$ \\ Faizah $^{2}$ \\ Ulifa Rahma ${ }^{3}$
}

\begin{abstract}
Bullying is a negative action done by someone to another person, which is done repeatedly, and arises because of intention, and there are differences in strength, both physical and mental. This behavior arises since elementary school age. The reason for the emergence in the context of the offender is because of the lack of empathy skills for others. Namely, unable to feel the emotional state of others, cognitively unable to understand and evaluate the emotional state of others. The purpose of this study was to determine the effectiveness of empathy character building programs in reducing bullying behavior in elementary school students in Malang City. The initial data extraction, the level of bullying on this schools is from medium to high. One group pre-post test research design. The method of data analysis uses pair sample t-test to test different scores before and after the program. The result is there are differences in bullying behavior between before and after the implementation program. The percentage tendency of bullying behavior decreases. Medium category, that is equal to $60 \%$, the number of students included in the low category is $30 \%$, and the high category is $10 \%$. Keywords: bullying; elementary school students; empathy character building,
\end{abstract}

\begin{abstract}
ABSTRAK
Bullying merupakan tindakan negatif yang dilakukan seseorang kepada oranglain, terjadi secara berulang, ada niatan, dan adanya perbedaan kekuatan, baik fisik maupun mental. Perilaku tersebut muncul sejak usia sekolah dasar. Penyebab munculnya perilaku dalam konteks pelaku adalah karena kurangnya ketrampilan berempati kepada oranglain. Yaitu, tidak mampu merasakan kondisi emosi oranglain, dan secara kognitif tidak mampu memahami dan mengevaluasi keadaan emosi oranglain. Tujuan penelitian ini adalah untuk mengetahui keefektifan program emphaty character building dalam menurunkan perilaku bullying pada siswa SD Negeri di Kota Malang. Data awal, tingkat bullying siswa terentang dari sedang hingga tinggi. Desain penelitian one group pre-post test. Metode analisis data menggunakan pair sample t-test untuk menguji beda skor sebelum dan sesudah program. Hasilnya adalah terdapat perbedaan perilaku bullying antara sebelum dan setelah pelaksanaan program. Persentase jumlah siswa sekolah Dasar Negeri " $X$ " yang termasuk dalam kecenderungan perilaku bullying semakin menurun. Jumlah siswa yang termasuk kategori sedang, yaitu sebesar $60 \%$, kategori rendah sebesar 30\%, dan kategori tinggi sebanyak $10 \%$.
\end{abstract}

Kata kunci : bullying; empati character building; siswa sekolah dasar

\section{PENDAHULUAN}

Menurut data KOMNAS Perlindungan Anak (PA) dari tahun 2011 hingga Agustus 2014, KPAI mencatat 369 pengaduan terkait masalah bullying di bidang pendidikan. Hal tersebut adalah $25 \%$ dari seluruh pengaduan yang terjadi, yaitu sebanyak 1.480 kasus (Republika, 2014). Bullying ditunjukkan dari perilaku fisik, verbal, isyarat tubuh, baik individu maupun secara berkelompok (Rigby, 2002). Hal yang masuk dalam kategori perilaku bullying, yaitu tindakan negatif yang dilakukan oleh seorang siswa atau lebih, dilakukan berulang, muncul

\footnotetext{
${ }^{1}$ Yuliezar Perwira Dara, Universitas Brawijaya, perwiradara@ub.ac.id

${ }^{2}$ Faizah, Universitas Brawijaya, faizah_hermawan@ub.ac.id

${ }^{3}$ Ulifa Rahma, Universitas Brawijaya, ulifa_rahma@ub.ac.id
} 
karena ada perbedaan kekuatan/kekuasaan (fisik maupun mental). Hal yang terakhir tersebut yang membedakan dengan agresivitas. Penyebab munculnya perilaku Bullying ditinjau dari konteks pelaku, adalah karena kurangnya ketrampilan berempati kepada oranglain (Dautenhahn, Woods \& Kaouri (2007), dan kurang memahami serta memikirkan perasaan orang lain (Randall, 1997); sedangkan dalam konteks korban, bullying muncul karena tidak berdaya dalam menghadapi pelaku bullying, dan keadaan fisik maupun mental yang lebih lemah dari pelaku (Olweus, dalam McEachern dkk, 2005). Hasil penelitian Faizah, Kurniawati \& Rahma (2015) menunjukkan bahwa empati siswa di jenjang pendidikan SD lebih rendah dibanding jenjang pendidikan yang lainnya.

Data menunjukkan bahwa 67,66\% kejadian bullying terjadi di sekolah. Perilaku bullying muncul bahkan sejak usia Sekolah Dasar (Olweus, 1991; Rigby, 2007; Pratiwi, 2016) dan di Australia (Peterson dan Rigby) diketahui bahwa bullying yang biasa terjadi di sekolah mulai meningkat pada awal secondary school atau setingkat dengan SMP. Usman (2013) mengungkapkan bahwa, faktor individual, hubungan keluarga, kelompok teman sebaya dan sekolah berperan pada kecenderungan bullying siswa. Menurut Goodwin (2009) anak akan terstimulasi menjadi pelaku bullying, ketika berada di lingkungan kelompok yang dapat menimbulkan perilaku bullying. KPAI menyatakan kelemahan dalam pengawasan di area sekolah juga dapat menjadi penyebab terjadinya Bullying (Merdeka.com, Agustus 2017).

Bentuk kejadian bullying yang terjadi dalam sekolah " $\mathrm{X}$ " diantaranya adalah pemalakan kepada adik tingkat, memukul dan menendang teman, mengejek, serta mengucilkan teman dengan tuduhan pencurian. Jenis-jenis tindak bullying tersebut termasuk bullying social, verbal serta fisik (Coloraso, 2007), namun tidak menutup kemungkinan akan munculnya bentuk lain.

Dampak yang timbul dari bullying bagi korban adalah, dapat mengalami depresi, kurang termotivasi dalam menyelesaikan tugas, hingga sulit untuk menjalin hubungan baik dengan oranglain (Berthold dan Hoover, 2000). Selain itu, korban mengalami kecemasan dan masalah fisik lainnya. Di Kota Malang, Bullying banyak mengakibatkan siswa merasa enggan untuk masuk sekolah (school refusal), karena adanya tekanan yang kerap mereka alami selama di sekolah (Republika Malang, 2016). Bahkan sudah banyak dampak berupa kematian yang dilaporkan di berbagai media, salah satunya kejadian yang terjadi di salah seorang siswa SD di Sukabumi pada Agustus 2017 lalu (Merdeka.com, Agustus 2017). Dampak bagi pelaku salah satunya adalah bermasalah dalam hal akademis (Masruroh, Mufidah, A; 2016)

Perguruan tinggi menjadi institusi yang dapat bekerja sama dengan masyarakat dan sekolah dalam membantu mencegah maupun meminimalisir kejadian bullying. Salah satu cara untuk menangani masalah bullying adalah melalui pelatihan pembentukan karakter empati (Stanbury, dkk, 2009; Faizah, Yunita, Ulifa, 2016). Empati secara umum didefinisikan sebagai kemampuan merasakan perasaan oranglain (Faizah, Yunita, Ulifa, 2016). Beberapa ahli menyatakan bahwa empati merupakan dasar ketrampilan interaksi social (Bohart \& Greenberg, 1997). Jolife \& Farrington (2006) menyatakan bahwa seseorang dengan empati yang rendah, kurang mampu merespon tekanan dan ketidaknyamanan yang dirasakan oleh oranglain. Empati yang mempengaruhi munculnya kecenderungan bullying disusun oleh dua komponen, yaitu komponen afektif dan kognitif (Mitsopoulou \& Giovazolias, 2015; Zoll \& Enz (2010)). Komponen afektif dalam konteks bullying, adalah ketidakmampuan merasakan kondisi emosi oranglain yang menjadi sasaran; sedangkan komponen kognitif, yaitu ketidakmampuan seseorang dalam memahami dan mengevaluasi keadaan emosi oranglain yang menjadi sasaran perilaku bullying.

Memperhatikan dampak jangka panjang dari kejadian bullying, maka peneliti melakukan penelitian dalam tujuan untuk melihat efektivitas program pembentukan karakter empati apakah mampu menurunkan persentase kejadian bullying di sekolah dasar negeri " $\mathrm{X}$ " di Kota Malang. 


\section{METODE PENELITIAN}

Variabel dalam penelitian ini adalah perilaku bullying dan karakter empati, dengan subyek siswa SD Negeri Kota Malang yang dalam pengamatan dan pengukuran melalui skala bullying mereka termasuk dalam kategori sedang hingga tinggi dalam perilaku bullyingnya di sekolah. Metode penggalian data melalui observasi, wawancara, dan skala bullying dan empati. Upaya yang dilakukan adalah melalui pelatihan pembentukan karakter empati (empathy character building training) untuk menangani kejadian bullying tersebut. Materi training berdasarkan hasil penelitian Faizah, dkk (2016) dengan memodifikasi hasil penelitian dari Stanbury, dkk (2009). Pembentukan empati, dibangun dari beberapa komponen, yaitu kognitif atau pemahaman serta komponen afektif, yang dalam pelaksanaannya dilakukan dalam enam sesi aktivitas.

Program terdiri dari beberapa aktivitas yang terbagi dalam 2 kegiatan besar, yaitu emphaty character building dan emphaty character building on behaviour. Sesi 1 mengenai pengenalan konsep bullying dalan konteks kognitif dan afektif, sesi 2: cerita pendek, sesi 3: penggosip, sesi 4: audiotape, sesi 5: refleksi pasta gigi dan uniknya kelinci Larry, sesi 6: the freshman, sesi 7: pengisian post test. Dari masing-masing sesi memiliki pertanyaan refleksi yang berbeda-beda dikaitkan dengan materi.

\section{HASIL DAN PEMBAHASAN}

Tabel 1.

Uji Perbedaan Bullying Siswa Sebelum dan Sesudah Diberikan pelatihan Emphaty Character Building

\begin{tabular}{llll} 
& Mean & N & std dev \\
Pre bullying & 60,733 & 30 & 5,699 \\
Post bullying & 53,667 & 30 & 10,710 \\
\hline
\end{tabular}

Efektifitas pelatihan empathy character building dapat diketahui dari nilai signifikansi sebesar 0.00 dengan nilai korelasi 0,47 yang menunjukkan hasil yang cukup baik.

Berdasarkan hasil uji t diperoleh nilai rata rata sebelum pelaksanaan pelatihan emphaty character building 60,733 dan setelah pelatihan sebesar 53, 677 dengan selisih 7,066, yang terdapat perbedaan perilaku bullying antara sebelum dengan setelah pelaksanaan program. Hasilnya diketahui bahwa terdapat penurunan tingkat bullying sebesar 7,066 pada siswa SDN kota Malang setelah melalui pelatihan Emphaty Character Building

Perubahan ini diperoleh dari skor per siswa bahwa periilaku bullying menurun dari tingkat sedang yang awalnya 27 siswa, menurun menjadi 18 siswa dan 9 lainnya termasuk kategori bullying rendah. Sedangkan jumlah siswa yang termasuk memiliki tingkat bullying yang tinggi masih tetap terdapat 3 siswa.

Tabel 2.

Kategorisasi Emphaty Character Building setelah pelaksanaan Pelatihan Siswa SDN kota Malang. 
YULIEZAR PERWIRA DARA, FAIZAH, \& ULIFA RAHMA, Are You Bullied? : Empathy Character Building Training Pada Siswa Sekolah Dasar

\begin{tabular}{cccc} 
Kategori & $\begin{array}{c}\text { Daerah } \\
\text { keputusan }\end{array}$ & Frekuensi & $\begin{array}{c}\text { Persentase } \\
(\boldsymbol{\%})\end{array}$ \\
\hline Rendah & $\mathrm{X}<46$ & 9 & $30 \%$ \\
Sedang & $\mathbf{4 6} \leq \mathbf{X}<\mathbf{6 9}$ & $\mathbf{1 8}$ & $\mathbf{6 0 \%}$ \\
Tinggi & $69<\mathrm{X}$ & 3 & $10 \%$ \\
\hline Total & & 30 & $100 \%$ \\
\hline
\end{tabular}

Dapat diketahui bahwa dominasi presentase bullying siswa SDN kota malang masuk dalam kategori sedang yaitu sebesar $60 \%$. Sedangkan $30 \%$ masuk dalam kategori rendah dan $10 \%$ masuk dalam kategori tinggi.

Hasil kegiatan pelatihan empathy character building menunjukkan bahwa terdapat perubahan perilaku bullying siswa SDN " $X$ " di Kota Malang setelah diberikan pelatihan, dengan perubahan sebesar 7,066. Efektifitas pelatihan empathy character building dapat diketahui dari nilai signifikansi sebesar 0.00 dengan nilai korelasi yang menunjukkan hasil yang cukup baik. Hal ini senada dengan yang dijelaskan oleh Gerdes \& Segal (2009) bahwa kemampuan empati pada seseorang memiliki korelasi terhadap perilaku bullying. Empati berkaitan dengan perilaku bullying yaitu semakin tinggi level empati seseorang maka semakin kecil kemungkinan seseorang tersebut menjadi pelaku bullying. Studi di luar negeri yang dilakukan oleh Stanbury dkk (2009) dari Amerika Serikat pernah melakukan penelitian tentang "The Effects Of An Empathy Building Program On Bullying Behaviour". Menghasilkan bahwa program pembangunan empati memiliki efek positif terhadap penurunan perilaku bullying.

Dalam program emphaty character building ini membidik aspek kognitif, afektif dan perilaku. Hal ini senada dengan penelitian Lestari (2013) dan Saripah (2010) menggunakan aspek kognitif dan afektif dari empati dalam proses konseling sehingga secara efektif menurunkan agresi perilaku bullying. Menurut Yusuf dan Fahrudin (2012) terdapat program pencegahan bullying dengan menyampaikan pesan bahwa perilaku bullying tidak dapat diterima di sekolah.

Pelatihan tidak hanya disampaikan melalui ceramah namun terdapat sesi diskusi, refleksi untuk membidik pengetahuan dan pemahaman siswa serta role play agar siswa mampu mengaplikasikannya dalam bentuk perilaku. Flora (2014) menggunakan metode role playing melalui konseling kelompok dan Afriana (2013) juga menggunakan konseling kelompok untuk mengurangi perilaku bullying. Menurut Howe (2015) munculnya empati pada anak mendorong perilaku peduli terhadap orang lain. Empati pada anak - anak dengan merenungkan pengalaman orang lain, membaca sebuah buku fiksi, bermain peran atau menyaksikan sebuah film bertemakan empati dapat menurunkan terjadinya perilaku - perilaku bullying yang dilakukan oleh siswa di Sekolah Dasar. Damon (2010) menemukan bahwa anak dengan usia 10 tahun hingga 12 tahun mampu mengembangkan empati dengan merespon kondisi yang dialami oleh orang lain. Empati yang dimiliki oleh anak yang berusia 10 tahun hingga 12 tahun dapat terwujud dalam kepeduliannya terhadap orang lain (Santrock, 2007). Hal tersebut didukung oleh penelitian Retnaningsih (2005) dan Fidrayani (2015) anak usia sekolah dasar menunjukkan perilaku prososial, nilai - nilai dari pengalaman empati, perilaku menolong orang lain dan bekerjasama dibandingkan pada fase usia remaja.

Perubahan ini dapat dilihat dari skor per siswa bahwa periiaku bullying menurun dari tingkat sedang yang awalnya 27 siswa, menurun menjadi 18 siswa dan 9 lainnya termasuk kategori bullying rendah. Sedangkan jumlah siswa yang termasuk memiliki tingkat bullying yang tinggi masih tetap terdapat 3 siswa.Dapat diketahui bahwa dominasi presentase bullying siswa SDN kota malang masuk dalam kategori sedang yaitu sebesar 60\%. Sedangkan 30\% masuk dalam kategori rendah dan $3 \%$ masuk dalam kategori tinggi. Menurut Damon dalam Santrock (2007) menemukan bahwa anak usia sekolah dasar dengan usia 10 - 12 tahun dapat merespon kondisi atau keadaan yang dialami oleh orang lain. Film kebaikan tersebut 
menggambarkan untuk mengenali keberadaan orang lain dengan merasakan berada di posisi orang lain seperti peka terhadap orang lain dan perilaku lain yang menggambarkan nilai - nilai empati pada aspek afektif ini. Dengan melakukan pelatihan emphaty character building pada anak usia sekolah dasar yang berusia 10-12 tahun melalui pelatihan dan praktik, maka anak lebih mewujudkan kepedulian, menolong orang lain dan nilai - nilai kebaikan diri yang terwujud dalam empatinya (Howe, 2012).

Analisis tambahan mengenai implementasi program per sesi dari sesi kegiatan storytelling dan penggosip juga menunjukkan kontribusi dapat menurunkan perilaku bullying dengan memberikan pemahaman dan mengajarkan mengenai perilaku empati. Hal ini nampak dari observasi kepada siswa yang semakin bertambah kesadarannya dengan mengingatkan teman yang menggoda teman lain, dan menunjukkan sikap empati. Hal tersebut sejalan dengan penelitian Anggraeni (2009). Selain itu, Asfandiyar (2007) menyatakan bahwa storytelling merupakan seni bercerita sebagai sarana menanamkan nilai-nilai pada anak, tanpa menggurui sang anak.

\section{KESIMPULAN}

Hasil kegiatan pelatihan empathy character building menunjukkan bahwa program emphaty character building untuk siswa SDN "X" di Kota Malang cukup efektif menurunkan perilaku bullying, dengan perubahan sebesar rerata 7,066. Dominasi persentase bullying siswa SDN "X" kota Malang masuk dalam kategori sedang yaitu sebesar 60\%. Sedangkan 30\% masuk dalam kategori rendah dan $10 \%$ masuk dalam kategori tinggi

Berdasarkan hasil, diketahui bahwa program pelatihan empathy character building bagi siwa SD dapat menurunkan perilaku bullying, sehingga dapat menjadi referensi kegiatan melalui program sekolah. Program dapat diterapkan melalui proses belajar mengajar yang dengan menyisipkan materi/pemahaman mengenai sikap dan perilaku/nilai moral, khususnya sikap empati. Kegiatan dapat pula disampaikan dengan menambahkan psikogames sederhana sehingga bisa diterapkan saat kegiatan outdoor yaitu dalam mata pelajaran olah raga dengan tetap memberikan refleksi mengenai sikap empathy kepada siswa, sehingga menjadi alternatif metode agar peserta tidak jenuh. Masing-masing sesi kegiatan dalam modul

\section{DAFTAR PUSTAKA}

Afriana, D. (2013). Upaya mengurangi perilaku bullying di sekolah dengan menggunakan layanan konseling kelompok. Fakultas Keguruan Dan Ilmu Pendidikan, 1-15.

Anggraeni,D. (2009). Program Bimbingan Pribadi-Sosial Untuk meningkatkan Perilaku Prososial Siswa. (Tesis tidak dipublikasikan). Sekolah Pascasarjana UPI, Bandung:

Asfandiyar, Andi Yudha. (2007). Cara pintar mendongeng. Bandung: Mizan Media Utama.

Berthold, K. A., \& Hoover, J. H. (2000). Correlates of bullying and victimization among intermediate students in the Midwestern USA. Journal of School Psychology International, 21, 65-78

Bohart, A. C., \& Greenberg, L. S. (1997). Empathy and psychotherapy: An introductory overview. In A. C. Bohart \& L. S. Greenberg (Eds.), Empathy reconsidered: New directions in psychotherapy (pp. 3-31). Washington, DC, US: American Psychological Association. http://dx.doi.org/10.1037/10226-018

Coloraso, B. (2007). The Bully, the bullied, and the bystander. New York: Harper Collins.

Damon, W. (2010). The moral child: Nurturing children's natural moral growth. New York: The Free Press.

Dautenhahn, S. Woods and C. Kaouri. (2007). Possible connections between bullying behaviour, empathy and imitation. In: K. 
YULIEZAR PERWIRA DARA, FAIZAH, \& ULIFA RAHMA, Are You Bullied? : Empathy Character Building Training Pada Siswa Sekolah Dasar

$\overline{\text { Dautenhahn and C. Nehaniv. Editors. (2007). Models and mechanisms of imitation and social }}$ learning in robots, humans and animals: Behavioural social and communicative dimensions. Cambridge University Press, Cambridge, pp. 323-339.

Faizah, F., Rahma, U., Kurniawati, Y. (2018). Program empathy character building untuk menurunkan perilaku bullying pada siswa SMP Inklusi. Jurnal Humanitas, 15 (2), 137144.

Fidrayani. (2015). Pengembangan Empati Pada Anak Usia Sekolah Dasar. Seminar Psikologi dan Kemanusiaan, Universitas Muhammadiyah Malang, 125-130

Flora, R. (2014). Mengurangi perilaku bullying kelas X-4 melalui pemberian layanan bimbingan kelompok teknik roleplay di SMA Negeri 12 Medan tahun ajaran 2012/2013. Jurnal Saintech, 06 (2), 34-44.

Gerdes, K.E and Segal, E.A. (2009). A Social Work Model Of Empathy. Advance In Social Work, 10 (2): 114-127

Goodwin, D. (2010). Strategies to Deal with Bullying (Strategi Mengatasi Bullying). Wellington Australia: Kidsearch Inc.

Howe, D. (2015). Empati Makna dan Pentingnya. Yogyakarta : Pustaka Pelajar

Jolliffe, D \& Farrington, D.P. (2006). Examining the relationship between low empathy and bullying. Aggressive Behaviour. 32 (6), 540-550.

Lestari, D. (2013). Menurunkan perilaku bullying verbal melalui pendekatan konseling singkat berfokus solusi. Jurnal Pendidikan Penabur, 21-36

Masruroh, N., Mufidah, C., A, I, R. (2016). Pengalaman bullying berdasarkan perspektif pelaku, korban, dan saksi mata pelajar SMP X Kota Batu. Jurnal UMM, 7(2), 109-117. http://ejournal.umm.ac.id/index.php/keperawatan/issue/view.

Mitsopoulou, E. \& Giovazolias, T. (2015). Personality Traits, empathy and bullying behavior: A Meta-analytic approach. Aggression and Violent Behavior, (21), 61-72

McEachern, A.G., Kenny, M., Blake, E., \& Aluede, O. (2005). Bullying in school: International variation. Journal of Social Science Special Issue, 8: 51-58.

Olweus, D. (1991). Bully/victim problems among schoolchildren. Basic fact and effects of school based intervention program. In D. Pepler \& K. Rubin (Eds)., The development and treatment of childhood aggression (pp.411-448).

Pratiwi, J.I. (2016). Perbedaan perilaku overt aggresion pelaku bullying antara siswa SD-SMP di Kota Malang. Skripsi: Universitas Brawijaya. https://prasetya.ub.ac.id/press/GowezAssisstance-dan-Bullying-Raih-NilaiSempurna-dalam-Penelitian-18843-id.html

Randall. (1997). Adult Bullying: Perpetrators and victims. London: Routledge

Retnaningsih. (2005). Peranan Kualitas attachment, usia dan gender pada perilaku prososial. Proceeding Seminar Nasional Auditorium Universitas Gunadarma, 9-17

Rigby, K. (2002). New Perspectives on Bullying. London : Jessica Kingsley.

Rigby, K. (2007). Bullying in school and what to do about it. Victoria: ACER Press.

Santrock, J. W. (2007). Perkembangan Anak Jilid 1. Jakarta : Erlangga

Saripah, I. (2010). Model konseling kognitif perilaku untuk menanggulangi bullying siswa. Proceedings Of The 4 th International Conference On Teacher Education : Join Conference Upi \&Upsi Bandung, Indonesia 720- 726

Stanburry, S., Bruce, M.A., Jain, S., Stellern, J. (2009). The effect of an emphaty building program on bullying behaviour. Journal of School Counseling, 7(2), 1-27.

Usman, I. (2013). Kepribadian, komunikasi, kelompok teman sebaya, iklim sekolah dan perilaku Bullying. Jurnal Humanitas, 10, (1), DOI: http://dx.doi.org/10.26555/humanitas.v10i1.328

Yusuf, H \& Adi F. (2012). Perilaku bullying : Asesmen multidimensi dan intervensi sosial. Jurnal Psikologi Undip, 11(2) : 1-10

Zoll, C., \& Enz, S.(2010). A questionnaire to assess affective and cognitive empathy in 
children. OPUS publication server.

Christiyaningsih. (April, 2016). Aduan 'School Refusal' Meningkat di Kota Malang. https://nasional.republika.co.id/berita/nasional/daerah/16/04/26/o683ag328-aduanschool-refusal-meningkat-di-kota-malang.

Malangtoday.net. (Oktober, 2017). Tekan angka kasus bullying, Dharma Wanita Kota Batu Tekankan Peran Guru. https://malangtoday.net/malang-raya/batu/tekan-angka-kasusbullying-dharma-wanita-kota-batu-tekankan-peran-guru/

Sholeh, M. (Agustus, 2017). Kasus siswa SD tewas di-bully, KPAI sebut sekolah tak lagi aman. Merdeka.com. https://www.merdeka.com/peristiwa/kasus-siswa-sd-tewas-di-bullykpai-sebut-sekolah-tak-lagi-aman.html. 